\title{
Severe community onset healthcare-associated Clostridium difficile infection complicated by carbapenemase producing Klebsiella pneumoniae bloodstream infection
}

\author{
Simone Giuliano ${ }^{1 \dagger}$, Maurizio Guastalegname ${ }^{1 \dagger}$, Miryam Jenco ${ }^{2}$, Andrea Morelli³, Marco Falcone \\ and Mario Venditti ${ }^{1 *}$
}

\begin{abstract}
Background: Clostridium difficile infection (CDI) and Klebsiella pneumoniae carbapenemase producing-Klebsiella pneumoniae (KPC-Kp) bloodstream infection (BSI) are emerging health-care associated (HCA) diseases of public health concern, in terms of morbidity, mortality, and insufficient response to antibiotic therapy. Both agents can be acquired in the hospital but clinical disease can develop in a community setting, after discharge. We report here a putative link between the above-mentioned healthcare associated infections that appeared as a dramatic community onset disease with a fulminant fatal outcome.

Case presentation: We describe the case of a 63 year old man affected by severe CDI. Even though the patient underwent 72 hours of standard CDI antibiotic treatment, the clinical course was complicated by toxic megacolon and KPC-Kp BSI. The patient died 24 hours after total colectomy.

Conclusion: The impact of HCA-BSIs in complicating CDI is still unknown. Intestinal inflammatory injury and disruption of intestinal flora by standard antibiotic treatment could be responsible for promoting difficult-to-treat infections in CDI. By preserving intestinal flora, Fidaxomicin could have a crucial role in preventing BSIs complicating severe CDI.
\end{abstract}

Keywords: Clostridium difficile, Klebsiella pneumoniae, KPC, Bloodstream infections, Intestinal flora, Fidaxomicin

\section{Background}

The impact of health-care associated (HCA) bloodstream infection (BSI) in complicating Clostridium difficile infection (CDI) is still unknown. We describe for the first time a case of community onset healthcare-associated severe CDI complicated by Klebsiella pneumoniae Carbapenemase producing Klebsiella pneumoniae (KPC-Kp) BSI. $\mathrm{CDI}$ and KPC-Kp BSI are recently emerging as two of the more concerning HCA diseases in terms of morbidity, mortality, and inefficient response to antibiotic therapy. A relation between the above-mentioned infections have never been reported until now.

\footnotetext{
* Correspondence: mario.venditti@uniroma1.it

${ }^{\dagger}$ Equal contributors

'Department of Public Health and Infectious Diseases Policlinico Umberto I, "Sapienza" University of Rome, Viale del Policlinico 155, 00161 Rome, Italy Full list of author information is available at the end of the article
}

\section{Case presentation}

We report the case of a 63 year old man, who was admitted on the 6th of February 2014 to the Intensive Care Unit (ICU) of a 1300-bed teaching Institution in Rome because of septic shock syndrome. His past medical history was remarkable for high blood pressure, multi-infarct dementia, Parkinson's disease and depressive disorder. The patient had been hospitalized on the 15th of January 2014 in a peripheral center for a febrile syndrome due to a urinary tract infection caused by Escherichia coli. During his hospital stay, he underwent a ten-day course of antimicrobial therapy with intravenous ciprofloxacin and was discharged on the 28th of January on treatment with oral Cefditoren pivoxil. On the 3rd of February, the patient was readmitted to the same hospital because of confusion, fever and diarrhea. Clostridium difficile infection (CDI) test was performed (Alere ${ }^{\text {Tw }}$ C. DIFF QUICK CHECK 
COMPLETE for simultaneous detection of both glutamate dehydrogenase antigen and toxin A and B). Oral vancomycin $500 \mathrm{mg}$ q6h, intravenous metronidazole $500 \mathrm{mg}$ q6h and intravenous Piperacillin/tazobactam $4.5 \mathrm{~g}$ q8h were immediately started. After 72 hours of persistent deterioration despite standard antibiotic therapy administration, the patient was transferred to the ICU of our hospital. At the admission the patient was unconscious (Glasgow Coma Scale of 3), presenting with ileus and septic shock syndrome. Oro-tracheal intubation and fluid resuscitation were performed followed by intravenous norepinephrine. Tigecycline was empirically added to the combination antimicrobial therapy. Three blood cultures were drawn and blood test showed 24000 white blood cells $/ \mu \mathrm{l}$, creatinine $3.6 \mathrm{mg} / \mathrm{dl}$, albumin $2.2 \mathrm{~g} / \mathrm{dl}$, lactate $4 \mathrm{mmol} / \mathrm{l}$. Computed tomography scans demonstrated findings compatible with toxic megacolon. A total colectomy was performed but the patient died $24 \mathrm{~h}$ after the surgical intervention. All blood cultures drawn at the time of admission to the ICU were positive for a carbapenemresistant strain of Klebsiella pneumoniae (Vitek 2 system, AST-N089 card bioMérieux, Marcy l'Etoile, France, MICs: Amikacin $\geq 64 \mathrm{mg} / \mathrm{l}$, Amoxicillin/Clavulanic acid $\geq 32 \mathrm{mg} / \mathrm{l}$, Cefepime $\geq 64 \mathrm{mg} / \mathrm{l}$, Cefotaxime $\geq 64 \mathrm{mg} / \mathrm{l}$, Ceftazidime $\geq$ $64 \mathrm{mg} / \mathrm{l}$, Ciprofloxacin $\geq 4 \mathrm{mg} / \mathrm{l}$, Colistin $\geq 16 \mathrm{mg} / \mathrm{l}$, Ertapenem $\geq 8 \mathrm{mg} / \mathrm{l}$, Fosfomycin $\geq 256 \mathrm{mg} / \mathrm{l}$, Gentamicin $4 \mathrm{mg} / \mathrm{l}$, Imipenem $\geq 16 \mathrm{mg} / \mathrm{l}$, Meropenem $\geq 16 \mathrm{mg} / \mathrm{l}$, Piperacillin/ Tazobactam $\geq 128 \mathrm{mg} / \mathrm{l}$, Tigecycline $4 \mathrm{mg} / \mathrm{l}$, Trimethoprim/ Sulfamethoxazole $\geq 320 \mathrm{mg} / \mathrm{l}$ ). Production of KPC enzyme was documented by using a phenotypic test based on the inhibitory activity of boronic acid compounds as reported by Pournaras et al. [1], and carbapenemase producingKlebsiella pneumoniae (KPC-Kp) was identified. In addition, one blood culture was positive for vancomycinsusceptible Enterococcus faecium. Histologic examination of the colon confirmed diagnosis of pseudomembraneous colitis.

\section{Discussion and conclusion}

We believe that this case report is of great interest because our patient contemporarily developed two communityonset healthcare associated infections with a rapidly fatal outcome. Carbapenem-resistant Enterobacteriaceae (CRE) are an emerging issue of great public health concern. In our country, the problem is almost completely represented by carbapenem-resistant $K$. pneumoniae. Even though data related to incidence are missing, percentage of invasive $K$. pneumoniae isolates with resistance to carbapenems reportedly ranges between $25 \%$ and $50 \%$ in Italy [2]. Recently, cases of healthcare-associated carbapenem resistant $K$. pneumoniae BSIs have been reported in Northern Italy [3]. The phenomenon is also well known in Rome [4] and parallels to an epidemiological shift of CDI occurring in our region and consisting of increased disease incidence and mortality rates $[5,6]$, that are probably due to the spread of the epidemic strain ribotype $027 \mathrm{CD}$ [6-8]. In the present case, because the initial diagnosis was made in a peripheral center, ribotyping test was not performed. We describe, for the first time, a fatal case of severe CDI complicated by KPC-Kp BSI. This led us to question about the role of severe $\mathrm{CDI}$ on predisposing to $\mathrm{HCA}-\mathrm{BSIs}$, and vice-versa, on the role of HCA-BSIs in determining the prognosis of severe $\mathrm{CD}$ colitis. To our knowledge this issue has never been thoroughly evaluated in the literature until now.

We already disserted on the putative correlation between CDI and Candida spp. BSI [9]. Analogous mechanisms could be advocated to explain the link between CDI and KPC-Kp BSI. Recently, Perez et al. demonstrated in a mouse model the impact of the administration of antibiotics effective against intestinal flora on promoting the persistence of KPC-Kp colonization of the gastrointestinal tract [10]. Edlund et al., evaluating the ecological disturbances of oral vancomycin following cephalosporin administration in 20 healthy volunteers, showed intestinal Klebsiella spp. overgrowth within 3 days of vancomycin treatment [11]. In the present case, KPC-Kp colonization was acquired in a non-ICU setting, an emerging phenomenon already described in our country [12]. Oral vancomycin administration, highly active against the intestinal flora [13], could have been responsible for persistence and overgrowth of KPC-Kp in the gastrointestinal tract. Gut inflammatory injury caused by severe CDI could be considered the "second hit" allowing bacterial translocation and BSI. The role of severe intestinal inflammation predisposing to bacterial mucosal penetration and blood invasion has been already showed in murine and human models $[14,15]$. Moreover, K. pneumoniae has been demonstrated to be one of the most efficient microorganisms in translocating to extraintestinal sites, presenting a very low bacteremia clearance in the liver and spleen [16].

Colonic inflammation induced by severe CDI and standard $\mathrm{CD}$ antibiotic treatment could promote difficult-totreat infections/colonizations (i.e. KPC-Kp BSI, Candida spp. BSI [6], or vancomycin resistant-enterococci intestinal colonization [17]. Fidaxomicin, a newly licensed macrocyclic antibiotic recently approved to treat CDI, is characterized by a narrow spectrum of activity almost limited to $\mathrm{CD}$ and consequent preservation of intestinal flora compared to vancomycin [13]. Preservation of intestinal flora could represent a useful therapeutic option not only in reducing CDI recurrence rate [9], but also in preventing BSIs secondary to severe CDI.

In conclusion, clinical impact of BSIs on complicating CDI has not been systematically evaluated until now. Fidaxomicin could represent a useful therapeutic option in preventing difficult-to-treat BSIs secondary to severe CDI. Studies are necessary to validate this hypothesis. 


\section{Consent}

Written informed consent was obtained from the next of a kin of the patient for publication of this Case report. A copy of the written consent is available for review by the Editor of this journal.

\section{Competing interests}

The authors declare that they have no competing interests.

\section{Authors' contribution}

All authors read and approved the final manuscript. SG and MG have made substantial contribution to concept and design of the manuscript. MJ has made contribution to acquisition of data. AM, MF and MV revised the manuscript for important intellectual content and final approval.

\section{Ackowledgements}

The authors are grateful to Dr M.A. Aruc for his contribution in revising the article critically for important intellectual content.

\section{Author details}

'Department of Public Health and Infectious Diseases Policlinico Umberto I, "Sapienza" University of Rome, Viale del Policlinico 155, 00161 Rome, Italy. ${ }^{2}$ Department of Anesthesiology and Intensive Care, "Villa San Pietro-Fatebenefratelli" Hospital, Rome, Italy. ${ }^{3}$ Department of Anesthesiology and Intensive Care, "Sapienza" University of Rome, Rome, Italy.

Received: 14 April 2014 Accepted: 18 August 2014

Published: 1 September 2014

\section{References}

1. Pournaras S, Poulou A, Tsakris A: Inhibitor-based methods for the detection of KPC carbapenemase-producing Enterobacteriaceae in clinical practice by using boronic acid compounds. J Antimicrob Chemother 2010, 65(7):1319-1321.

2. European Centre for Disease Prevention and Control: Antimicrobial resistance surveillance in Europe 2012. Annual Report of the European Antimicrobial Resistance Surveillance Network (EARS-Net). Stockholm: ECDC; 2013.

3. Corcione S, Cardellino CS, Calcagno A, Fossati L, Costa C, Cavallo R, Di Perri G, De Rosa FG: Healthcare-associated Klebsiella pneumoniae Carbapenemase producing K. pneumoniae bloodstream infection: the time has come. Clin Infect Dis 2014, 59(2):321-322.

4. Capone A, Giannella M, Fortini D, Giordano A, Meledandri M, Ballardini M, Venditti M, Bordi E, Capozzi D, Balice MP, Tarasi A, Parisi G, Lappa A, Carattoli A, Petrosillo N, SEERBIO-GRAB network: High rate of colistin resistance among patients with carbapenem-resistant Klebsiella pneumoniae infection accounts for an excess of mortality. Clin Microbiol Infect 2013,

19(1):E23-E30

5. Di Bella S, Musso M, Cataldo MA, Meledandri M, Bordi E, Capozzi D, Cava MC, Chiaradonna P, Prignano G, Petrosillo N: Clostridium difficile infection in Italian urban hospitals. Data from 2006 through 2011. BMC Infect Dis 2013, 13(1):146.

6. Guastalegname M, Grieco S, Giuliano S, Falcone M, Caccese R, Carfagna P, D'ambrosio M, Taliani G, Venditti M: A cluster of fulminant Clostridium difficile colitis in an intensive care unit in Italy. Infection 2014, 42(3):585-589.

7. Di Bella S, Paglia MG, Johnson E, Petrosillo N: Clostridium difficile 027 infection in Central Italy. BMC Infect Dis 2012, 12:370.1.

8. Orsi GB, Conti C, Mancini C, Giordano A: Clostridium difficile 027 increasing detection in a teaching hospital in Rome, Italy. Infection 2014, [Epub ahead of print].

9. Guastalegname M, Russo A, Falcone M, Giuliano S, Venditti M: Candidemia subsequent to severe infection due to Clostridium difficile: is there a link? Clin Infect Dis 2013, 57:772-774.

10. Perez F, Pultz MJ, Endimiani A, Bonomo RA, Donskey CJ: Effect of antibiotic treatment on establishment and elimination of intestinal colonization by KPC-Producing Klebsiella pneumoniae in mice. Antimicrob Agents Chemother 2011, 55(6):2585-2589.
11. Edlund C, Barkholt L, Olsson-Liljequist B, Nord CE: Effect of vancomycin on intestinal flora of patients who previously received antimicrobial therapy. Clin Infect Dis 1997, 25(3):729-732.

12. Richter SN, Frasson I, Franchin E, Bergo C, Lavezzo E, Cavallaro A, Palù G: KPC-mediated resistance in Klebsiella pneumoniae in two hospitals in Padua, Italy, June 2009-December 2011: massive spreading of a KPC-3-encoding plasmid and involvement of non-intensive care units. Gut Pathog 2012, 4(1):7.

13. Louie TJ, Cannon K, Byrne B, Emery J, Ward L, Eyben M, Krulicki W: Fidaxomicin preserves the intestinal microbiome during and after treatment of Clostridium difficile infection (CDI) and reduces both toxin reexpression and recurrence of $\mathrm{CDI}$. Clin Infect Dis 2012, 55(Suppl 2):S132-S142.

14. Johansson ME, Gustafsson JK, Holmén-Larsson J, Jabbar KS, Xia L, Xu H, Ghishan FK, Carvalho FA, Gewirtz AT, Sjövall H, Hansson GC: Bacteria penetrate the normally impenetrable inner colon mucus layer in both murine colitis models and patients with ulcerative colitis. Gut 2014, 63 (2):281-291.

15. Mainous MR, Tso P, Berg RD, Deitch EA: Studies of the route, magnitude, and time course of bacterial translocation in a model of systemic inflammation. Arch Surg 1991, 126(1):33-37.

16. Eaves-Pyles T, Alexander JW: Comparison of translocation of different types of microorganisms from the intestinal tract of burned mice. Shock 2001, 16(2):148-152.

17. Nerandzic MM, Mullane K, Miller MA, Babakhani F, Donskey CJ: Reduced acquisition and overgrowth of vancomycin-resistant enterococci and Candida species in patients treated with fidaxomicin versus vancomycin for Clostridium difficile infection. Clin Infect Dis 2012, 55(S2):S121-S126.

doi:10.1186/1471-2334-14-475

Cite this article as: Giuliano et al: Severe community onset healthcare-associated Clostridium difficile infection complicated by carbapenemase producing Klebsiella pneumoniae bloodstream infection. BMC Infectious Diseases 2014 14:475.

\section{Submit your next manuscript to BioMed Central and take full advantage of:}

- Convenient online submission

- Thorough peer review

- No space constraints or color figure charges

- Immediate publication on acceptance

- Inclusion in PubMed, CAS, Scopus and Google Scholar

- Research which is freely available for redistribution 